\section{RÉPLICA: EL PUNTO DE CORTE DE LA HEMOGLOBINA PARA DEFINIR ANEMIA MATERNA EN LA ALTURA NO DEBE SER CORREGIDO}

\section{RÉPLICA: EL PUNTO DE CORTE DE LA HEMOGLOBINA PARA DEFINIR ANEMIA MATERNA EN LA ALTURA NO DEBE SER CORREGIDO}

\author{
Oscar Munares-García ${ }^{1,2, a}$, \\ Guillermo Gómez-Guizado 1,b
}

Sr. Editor. El hierro es un micronutriente esencial, estudios no publicados realizados por el Centro Nacional de Alimentación y Nutrición del Instituto Nacional de Salud sobre consumo de hierro en hogares peruanos, nos indican que dicho consumo es bajo en la sierra rural $(58,8 \%)$ en comparación con la cifra a nivel nacional $(27,4 \%)$, este grupo es significativo en la sierra sur del Perú.

Con respecto a la comparación adaptativa de la hemoglobina en otras áreas geográficas, como los pobladores de los Himalaya y Etiopia, se sostiene que en dichas poblaciones los niveles de hemoglobina son similares a los niveles de pobladores de menor altitud, consideramos que esto puede tener una base evolutiva, pues ello está íntimamente relacionada con cambios en el ADN ${ }^{(1)}$, pues dichas poblaciones han tenido más tiempo para adaptarse y lograr esa modificación; son 40 mil años en esas zonas frente a los 10 a 12 mil años que tiene el poblador peruano en los andes; así mismo, se sabe que el poblamiento de América se originó en Asia; estudios de ADNmt han determinado que la variedad fenotípica de los pobladores de América, no es la misma que la variedad de los pobladores del sur de Asia (2), por ello, el tener más tiempo adaptándose y poseer otra variedad fenotípica hace que las evidencias en poblaciones himalayas y etíopes no necesariamente sean iguales a los mecanismos de adaptación del poblador andino.

Centro Nacional de Alimentación y Nutrición, Instituto Nacional de Salud. Lima, Perú.

2 Facultad de Medicina, Universidad Nacional Mayor de San Marcos. Lima, Perú.

a Licenciado en Obstetricia, magíster en Salud Pública, doctor en Ciencias de la Salud; ${ }^{\text {b }}$ Médico cirujano, especialista en Epidemiología de Campo. Recibido: 12-03-15 Aprobado: 18-03-15

Citar como: Munares-García O, Gómez-Guizado G. Réplica: El punto de corte de la hemoglobina para definir anemia materna en la altura no debe ser corregido [carta]. Rev Peru Med Exp Salud Publica. 2015;32(1):199.
En el artículo indicamos que hubo un alto porcentaje de cumplimiento de la suplementación, referido a un alto porcentaje de entrega del suplemento, que evaluó el Programa Articulado Nutricional, el indicador hace referencia a suplementos entregados, pero no precisa si dichos suplementos fueron consumidos, es decir, sí existió una adecuada adherencia al suplemento. Un estudio realizado en gestantes de Apurímac y Ayacucho encontró que el cumplimiento de las gestantes al consumo de sulfato ferroso a la primera visita fue del $70 \%$, pero luego este consumo cae bruscamente a la séptima visita $(33,3 \%)^{(3)}$, lo que nos sugiere que la estrategia está garantizando la entrega de suplementos, pero aún no está garantizando su consumo adecuado (adherencia). El reporte de datos sobre la anemia en nuestro país es presentado con corrección por la altura a nivel poblacional ${ }^{(4)}$, consideramos que no hay evidencia suficiente para opinar lo contrario, porque los estudios realizados en el país son de una muestra transversal, de base de datos secundaria que, si bien es cierto, pueden plantear dicha hipótesis, no podría mostrar una relación causal, porque no está diseñada para tal fin. Del mismo modo, dichos estudios, por ser transversales, no consideran variables de contexto socioeconómico, demográfico, cultural y costumbres e incluso comorbilidades, que podrían expresar los resultados perinatales adversos ya que la anemia no sería la única que explicaría dichos eventos, por lo que se requiere estudios longitudinales para confirmar tales hipótesis, tal como lo plantea el mismo autor en una publicación reciente ${ }^{(5)}$.

\section{REFERENCIAS BIBLIOGRÁFICAS}

1. Gutiérrez R, Martínez J, Vera J. Naturaleza y diversidad humana, estudios evolucionistas. Innovación Educativa 2014;14(66):179-185.

2. Pérez S. Poblamiento humano, diferenciación ecológica y diversificación fenotípica en América. Runa 2011;32(1):83-104.

3. Perú, Ministerio de Salud. Estudio de la adherencia a la suplementación con hierro durante la gestación en las direcciones de salud de Apurímac y Ayacucho. Lima: MINSA; 2009.

4. Instituto Nacional de Estadística e Informática. Perú Encuesta Demográfica y de Salud Familiar-ENDES: Nacional y Departamental 2013. Lima: INEI; 2014.

5. Gonzales GF, Tapia V, Gasco M, Carrillo CE, Fort AL. Association of hemoglobin values at booking with adverse maternal outcomes among Peruvian populations living at different altitudes. Int J Gynaecol Obstet. 2012 May;117(2):134-9. doi: 10.1016/j.ijgo.2011.11.024.

Correspondencia: Oscar Munares Garcia

Dirección: Av. Tizón y Bueno 276 Jesús María. Lima, Perú

Teléfono: 6176200 Anexo 6605

Correoelectrónico:omunares@ins.gob.pe 